Art. \# 806, 14 pages, http://www.sajournalofeducation.co.za

\title{
The challenges of realising inclusive education in South Africa
}

\author{
Dana Donohue and Juan Bornman \\ Centre for Augmentative and Alternative Communication, University of Pretoria, \\ South Africa \\ Juan.Bornman@up.ac.za
}

In South Africa, up to $70 \%$ of children of school-going age with disabilities are out of school. Of those who do attend, most are still in separate, "special" schools for learners with disabilities. This situation prevails despite the push for the educational inclusion of learners with disabilities over twelve years ago by the South African policy document, the Education White Paper 6. In this article, we take a primarily top-down theoretical approach to policy implementation and focus on two main factors that hinder the implementation of inclusive education. Firstly, we focus on what we regard as the most significant constraint, namely, the apparent lack of clarity in the policy, i.e. ambiguity about the goals for inclusion and the means through which they can be achieved and, secondly, various issues around the poor implementation of the policy. We argue further that the primary means by which the divide between inclusive policy and practice will ultimately be closed is through the implementation and enforcement of education policy by the South African Department of Education.

Keywords: disability, education policy, inclusive education, special schools

\section{Introduction}

The Education for All (EFA) initiative, first put forth in 1990 by the international community, marked a global movement towards providing quality basic education to all children, youth and adults (United Nations Educational, Scientific, and Cultural Organization (UNESCO), 1990). To accomplish this initiative, six specific goals were proposed, namely, provision and expansion of early childhood education; provision of free and compulsory education for all children of school-going age; provision of learning and life-skills programmes for adults; improvement of the adult literacy rate by $50 \%$ by the year 2015 ; elimination of gender inequality in education; and improvement of all aspects of education in order to provide quality education for all. In 2000, 189 countries renewed their commitment toward reaching these educational ideals through their adoption of the Millennium Development Goals (UNESCO, 2000), of which South Africa is a signatory.

In some respects, South Africa has met or nearly met these education goals. Unlike many other developing countries, there is no gender gap in the ultimate level of schooling attained for people of any age group in South Africa (Anderson, Case \& Lam, 2001). The adult literacy statistic is also relatively high, at $89 \%$. In contrast, the quality of general education is poor, with an ongoing national conversation about the crisis in education (Hay \& Beyers, 2011) marked by violence in schools, dropout, high teenage pregnancy rates, and decreasing high school graduation rates. Even when 
compared only to other African countries on standardised measures of achievement, South African learners still perform toward the bottom of the spectrum on both mathematics and reading (Van der Berg, 2007).

The current state of education in South Africa can, in part, be attributed to the legacy of the education policies instituted under apartheid. Engelbrecht (2006:254) states that " $[\mathrm{t}]$ he central feature which distinguishes South Africa from other countries in terms of education provision, is the extent to which racially entrenched attitudes and the institutionalisation of discriminatory practices led to extreme disparities in the delivery of education, a reflection of the fragmentation and inequality that characterised society as a whole". During apartheid, black South Africans received "Bantu Education", which provided limited instruction in mathematics and science and was instituted to direct non-white people into the unskilled workforce (Asmal \& James, 2001:186). Different ethnic groups were educated in separate facilities, where there were about twice as many learners per class in black as in white schools (Lomofsky \& Lazarus, 2001). Education for white pupils was compulsory, but not so for learners of other ethnicities (Asmal \& James, 2001). Schools were also segregated in terms of disability. Schools for white learners with disabilities were well-funded (Department of Education, 2001), whereas support services for learners with disabilities who attended black schools were uncommon (Department of Education, 2001; Lomofsky \& Lazarus, 2001).

Following the demise of apartheid, compulsory education was implemented for all South African children and segregated schooling practices were eliminated. One national Department of Education replaced the former 19 distinct departments with the goal of promoting educational equality (Maher, 2009). The new Department of Education attempted to redress some of the educational inequities between ethnic groups by providing low-income schools with a higher proportion of government subsidy (Lam, Ardington \& Leibbrant, 2008). Moreover, South Africa's new constitution included an explicit section on the rights of people with disabilities. The subsequent Education White Paper 6 (Department of Education, 2001:10) outlined the government's new policies for a single, undivided education system for all learners, including those with disabilities, in the hopes that inclusive education would provide "...a cornerstone of an integrated and caring society". This White Paper was designed to transform the South African educational system by building an integrated system for all learners (i.e. no special and ordinary schools); using a curriculum that is more flexible and suitable to the needs and abilities of learners; developing district-based support teams to provide systemic support for any and all teachers who need it; and strengthening the skills of teachers to cope with more diverse classes (Muthukrishna \& Schoeman, 2000).

Nevertheless, over a decade after the unveiling of Education White Paper 6 (Department of Education, 2001), most learners with disabilities who attend school are still in separate, "special" schools for learners with disabilities. There is no consensus 
about what should and should not be classified as a disability in South Africa (Heap, Lorenzo \& Thomas, 2009). This difference in opinion causes discrepancies in estimates of disability prevalence (Loeb \& Eide, 2004), despite the fact that the South African government has estimated that about $5 \%$ of the population have a disability (Statistics South Africa, 2011). In this paper, the definition of disability provided by the World Health Organization (WHO) will be used. According to WHO (2012), disability arises from the interaction between an impairment, in a person's body function or structure, and the society in which that person lives.

The purpose of this paper is to explore barriers that hinder the implementation of Education White Paper 6 (Department of Education, 2001). Many countries have struggled with bringing inclusive education policies into practice. To successfully implement inclusion anywhere in the world, educators must have adequate training, sufficient support, and positive attitudes (Frankel, Gold \& Ajodhia-Andrews, 2010). Positive caregiver attitudes also are important, as they can affect the time, resources and sacrifices that caregivers are willing to make and the degree of advocacy in which they are willing to engage to ensure their children receive the education to which they are entitled.

The unique history and diversity of South Africa as discussed earlier contribute to a context that can further complicate the conquering of barriers. The many different ethnic and language groups in South Africa, along with the country's apartheid history and rampant poverty, contribute to a society that has many different ideas not only about the needs of children with disabilities, but also about best practices and beliefs regarding how they should be educated. These complexities are a further hindrance to inclusive practices. However, we argue in this article that the primary explanation for the lack of any significant movement on inclusive policy is the apparent lack of clarity in the policy, as well as issues pertaining to the poor implementation of this policy. This is reflected in the inadequate funding provided by the South African Department of Education to the provincial education departments, as well as the vague guidelines and ambiguous incentives and directives they provide to educators. We begin the paper by discussing some of the school-level and cultural barriers to inclusion in South Africa; then we explore how Matland's (1995) top-down theoretical approach to policy implementation is applicable to Education White Paper 6 (Department of Education, 2001); and we conclude with some practical recommendations that may help bring inclusive policy to practice.

\section{School-level barriers to inclusion}

Estimates suggest that in all of Africa, only $10 \%$ of children with disabilities attend school (UNESCO, 2007). In South Africa, specifically, up to $70 \%$ of children of school-going age with disabilities are out of school (Department of Education, 2001), although school attendance is compulsory for all children between 7 and 15 years of age. Of those who do attend, most are still in separate, "special" schools for learners 
with disabilities. This situation still prevailed in 2013, despite the push for the educational inclusion of learners with disabilities more than a decade ago by the South African policy document, Education White Paper 6 (Department of Education, 2001). This document aimed to establish a system where, with the assistance of appropriate support, learners with disabilities learn alongside peers of the same age (Pivik, McComas \& Laflamme, 2002).

In recent years, the practice of inclusive education has been widely embraced as an ideal model for education, both in South Africa and internationally (Maher, 2009). However, this acceptance of ideal practices does not necessarily translate into what actually occurs within the classroom. Successful inclusion depends on the attitudes and actions of school principals (Zollers, Ramanathan \& Yu, 1999) and the investment of other school personnel as they create the school culture and have the ability to challenge or support inclusion (Ainscow, 2002). Research has found that although teachers often report that they agree with the idea of inclusion, they actually believe that the needs of learners with disabilities are best met in separate classrooms (Campbell, Gilmore \& Cuskelly, 2003), particularly those learners with greater special needs and more severe disabilities (Scruggs \& Mastropieri, 1996). According to Bornman and Rose (2010:7), "[a] general lack of support and resources, as well as the prevailing negative attitudes toward disability, all contribute to the general bewilderment in South African schools towards inclusion".

Contemporary teacher education in South Africa trains teachers how to accommodate diverse learners in a single classroom (Oswald \& Swart, 2011). This is in line with the social model of disability that views disability centrally as a social construct created by an ability-oriented environment. Disability, in this sense, sees the problem as located not in the individual, but in a societal, economic, political (and educational) system and culture that fail to meet the needs of these individuals (McEwan \& Butler, 2007). The social model is rooted firmly in the human rights paradigm, arguing for inclusion and the removal of all barriers that hinder full participation of individuals with disability. Before this model of disability was widely accepted, however, teachers in South Africa were trained to teach either general education or special education, being by-products of the tenets of the medical model. These practices have, in turn, produced many teachers without the necessary skills to teach learners with disabilities. They also created attitudes regarding the separate education of learners with disabilities that have become strongly embedded in the South African teaching culture (Ntombela, 2011). What further complicates matters is the fact that a large proportion of the South African teacher workforce is over 50 years of age (Armstrong, 2009); hence, reorienting teachers to new ways of educating learners after many years in the profession remains a significant challenge to inclusive practices.

New inclusive policies have demanded from teachers to challenge their existing schemas about best practices in the education of learners with disabilities, "....in some cases leading to cynicism, hopelessness, and a rejection of transformation policies" 
(Oswald \& Swart, 2011:391). Thus, ensuring that educators are not only supportive of inclusion policies but also willing to challenge outdated beliefs and practices continues to be a considerable barrier to inclusive education. Teachers' attitudes toward inclusion might become more positive if, along with training, they were to receive the appropriate service support for their learners with disabilities. Support provisions depend on the particular learner's impairment but may include special equipment, educational provisions and accommodations, for example, more time during test assessments; a teacher's aide to help provide the learner with a more intensive disability; one-on-one instruction). Support is a necessary component of successful inclusive education practices as the needs of many learners with disabilities are beyond the basic services available in typical general education classes (Lomofsky \& Lazarus, 2001). Yet, recent research involving school principals in Gauteng, the richest and most resourced province of South Africa, revealed that most learners with disabilities received specialised support services either "seldom" or "never" (Nel, Müller \& Rheeders, 2011:49).

\section{Cultural-level barriers to inclusion}

Polat (2011:57) suggests that resources and improved infrastructure are necessary but not sufficient for inclusion and that "[c]hanging attitudinal barriers among school professionals and in the wider community ... is one of the essential aspects of making inclusive education happen in low-income countries". The meaningful participation of children and adults with disabilities in the school and the community is affected by the cultural attitudes and values of its citizens. If a community expresses disregard and prejudice towards people with disabilities, then discriminatory practices will continue to be propagated.

Cultural attitudes about the importance of educating children with disabilities can affect whether or not parents decide to send them to school. Groce (2004) found that in various developing countries around the world children with disabilities often do not attend school because it is thought that they cannot learn or will be disruptive to other learners.

Parents also consider the financial expenditures relating to education in South Africa. Since many schools charge tuition fees, it may not be economically feasible for parents to send their child with a disability to school, particularly if they have other developing children of school-going age whose prospects of bringing in some sort of income are much better than those of their disabled child. Sparing the expense of school, some families also prefer to benefit from lobola, a custom practised primarily among black South Africans. Lobola is similar to a dowry, where a man pays his fiancée's family for her hand in marriage. This settlement can provide substantial financial benefits for the girl's family, particularly if they live in poverty.

In the KwaZulu-Natal province of South Africa, a study of teachers, parents, children and aid workers was undertaken to determine how these various parties 
perceived the extent to which inclusive education was being implemented in their communities (Maher, 2009). It was found that ostracism of learners with disabilities was perceived as a barrier by all participant groups. Teachers blamed negative societal attitudes toward disability for the stigmatisation of learners with disabilities within ordinary schools and considered this a justification for maintaining separate schools. Parents and children in this same study stated that learners may be safer in special schools for children with disabilities due to the intolerant attitudes of other children and school staff. In another study, caregivers of children with disabilities who lived in the Western Cape province of South Africa expressed similar fears concerning the mistreatment of their children in ordinary schools (Masasa, Irwin-Carruthers \& Faure, 2005 ), with $72 \%$ of the respondents stating that they believed their children with disabilities were better off in special schools.

Increasing attention has also been focused on the contrasting traditional and biomedical views of disability. Traditional views of disability are beliefs that have been handed down through generations, whereas the biomedical perspective refers to the scientific, evidence-based practice of modern medicine (Maloni, Despres, Habbous, Primmer, Slatten, Gibson \& Landry, 2010). In South Africa (Hosegood, PrestonWhyte, Busza, Moitse \& Timaeus, 2007) and neighbouring Zimbabwe (Jackson \& Mupedziswa, 1988), the traditional perspective attributes disability to family sin, witchcraft and angered ancestors. These perspectives sometimes lead to the mothers of children with disabilities being shunned and blamed for their child's disability by their families and communities (Daudji, Eby, Foo, Ladak, Sinclair, Landry, Moody \& Gibson, 2011; Department of Education, 1995), and to families hoping for their child with a disability to be "cured" (Masasa et al., 2005:43). These unique perspectives have also been found to differentially influence how caregivers approach the education, intervention and rehabilitation for their children with disabilities (Maloni et al., 2010). In fact, those who prescribe to traditional beliefs at times delay accessing modern medical interventions while they look for folk cures (Maloni et al., 2010; Masasa et al., 2005).

\section{Matland's top-down approach to policy implementation}

We argue that although there are many school-level and cultural barriers to inclusion, the major factors hindering the implementation of inclusive policy is the lack of clarity (ambiguity) in Education White Paper 6 (Department of Education, 2001) regarding the means through which schools can meet the goals of inclusive education. It is not clear whether this ambiguity is intentional, but it has undoubtedly led to inaction by the stakeholders involved. We take a primarily top-down theoretical approach to policy implementation (Matland, 1995) and argue that the primary means by which the divide between inclusive policy and practice ultimately will be closed is through the clarification of the means through which the relevant goals can be met and the enforcement of education policy by the South African national Department of Education. 
Top-down approaches stress the importance of policy clarity, as well as the control and direction by policymakers to systematically implement policy. Bottom-up approaches, on the other hand, highlight the importance of understanding the perspectives and experiences of target groups and service deliverers (Matland, 1995; Stofile, 2008). We prefer a top-down approach for inclusive policy implementation due to the many differing attitudes that create a context where there is little consensus about best education practices for children with disabilities. Hence, we believe that clear policy mandates, together with enforcement of such mandates, will be the most effective means by which inclusive policy will be realised in South Africa. Effective and clear legislation has been a primary means by which other countries (e.g. the United States) have established and supported inclusive practices (Frankel et al., 2010). Although we recognise that policy mandates are not the ultimate solution to make significant and lasting change in South Africa, we feel that reducing the ambiguity in the existing policies (i.e. stating goals more overtly as well as defining strategies on how to achieve them) and strengthening the enforcement of such policies promote the inclusion and participation of children with disabilities within the mainstream school system.

\section{Policy implementation challenges}

Education White Paper 6 includes six broad key strategies for establishing an inclusive education system: 1 ) the improvement of existing special schools and the conversion of some special schools to resource centres; 2) the mobilisation of nearly 300,000 children with disabilities who are of school-going age but not currently in school; 3) the conversion of some mainstream primary schools into full-service schools, which will be those schools that are inclusive; 4) the orientation of the staff and administration in mainstream schools to the tenets and practices of inclusive education, as well as how to make early identifications of children who may have disabilities; 5) the establishment of district-based support teams to help support educators with the process of implementing inclusive practices in their classrooms; and 6) the implementation of a national advocacy campaign to orient South Africans to the ideas of inclusive education, and the inclusion and participation of people with disabilities in society (Department of Education, 2001:20-23). These six strategies highlight the fact that Education White Paper 6 itself is lacking in specificity and detail, as it only has broad strategies, which give little guidance on how to effectively implement this policy in practice.

In addition to school- and cultural-level challenges to inclusion, difficulties associated with the implementation of inclusive policy appear to stem, in part, from the ambiguities within Education White Paper 6 (Department of Education, 2001). For example, the White Paper suggested the cost effectiveness of inclusion to be one of the benefits of inclusive policy (Department of Education, 2001). Yet, it is difficult to envisage how significant transformations to the educational system in South Africa (e.g. mobilisation of out-of-school children with disabilities; infrastructure changes to schools) can be made without providing provincial departments with substantial in- 
creases in their short-term funding to help take these necessary first steps (Stofile, 2008; Wildeman \& Nomdo, 2007). This ambiguity in financial means and departmental responsibilities may be intentional. Jansen (2001) suggests that some South African policies are enacted for their political symbolism rather than their practicality; thus, vague policies often get passed but no one is held accountable for their implementation. In fact, a chief complaint of education officials in the Eastern Cape province of South Africa was that they got the impression that the national Department of Education was not committed to the implementation of the inclusive policy and had tried to relegate their responsibilities to others (Stofile, 2008). The very same study found that school officials reported having received no support or funding from the Department of Education to help sustain any progress they had made in the implementation of some of the broad strategies mentioned in the White Paper. Without support and recognition, it is difficult for schools to make inclusion a reality.

According to Matland's (1995) ambiguity-conflict model of policy implementation, ambiguity in policy is the result of a lack of clarity in a policy document regarding the goals or the means by which such goals will be reached. When goals are not explicitly stated, there is uncertainty and misunderstanding about the purpose of policy. In studying the content of Education White Paper 6, it is clear that the proposed implementation strategies lack specificity and detail, thereby increasing the policy's ambiguity (Department of Education, 2001). Research found that education officials in South Africa were unsure regarding the goals of inclusive education, with some officials reporting they were unclear about how ordinary and special schools would be transformed into schools more suitable for inclusive education (Stofile, 2008). Other officials were confused about the parameters of barriers to learning and exactly how these barriers would be addressed within inclusive schools (Wildeman \& Nomdo, 2007). For example, trying to eliminate learners' intrinsic barriers (e.g. physical or sensory impairment) is more straightforward than trying to address some of their extrinsic barriers to learning (e.g. poverty or orphan-hood). If the goals of inclusion include addressing extrinsic barriers to learning, then schools would need more explicit guidelines from the Department of Education to help them accomplish this rather complicated task of implementing the inclusion policy.

Even more ambiguous than goals, the means by which the policies within Education White Paper 6 (Department of Education, 2001) will be realised, is not explicitly stated. Generally, when new policies have been implemented, sufficient funding and capacity to deliver these policies is assumed (Wildeman \& Nomdo, 2007). The Department of Education appears to have deficits in funding to provide to schools, while schools currently lack the capacity to accommodate diverse learners in one classroom. Initial funding will be necessary while schools locate out-of-school learners, buy devices for learners who need them, make the needed infrastructure changes to accommodate a diverse body of learners, and hire specialists who will provide specialised systemic support to teachers and schools that need assistance (Wildeman \& Nomdo, 2007). 
Added to a lack of funding, schools currently lack teachers who have the capacity and knowledge to instruct a diverse body of learners in a single classroom without considerably increasing their workload. Education White Paper 6 states that "[n]ew curriculum and assessment initiatives will be required to focus on the inclusion of the full range of diverse learning needs... since curricula create the most significant barrier to learning and exclusion for many learners" (Department of Education, 2001:31-32). How teachers are expected to accomplish the task of tailoring the curriculum to suit each learner's particular needs and pace of learning is not thoroughly detailed. The Department of Education envisaged that many teachers would be reoriented to new methods of teaching via comprehensive training programmes that they provided. Training programmes that educate teachers how to accommodate and teach learners with disabilities are generally a week or two long, but teachers report that although these brief training programmes are helpful, they are insufficient (Stofile, 2008). The programmes also tend to focus on developing a couple of skills, whereas teachers often need far more comprehensive training programmes.

Thus, to confirm what we have discussed above, ambiguities within Education White Paper 6 hinder inclusive practices. In addition, Matland's (1995) ambiguityconflict model suggests that policy implementation is hindered by conflict stemming from differences in opinion between various stakeholders about how the policy will be executed. According to Matland (1995:157), "[v]irtually all [policy theorists] have emphasised the importance of delegating policy to a sympathetic agency. Placing a policy in an agency where it conflicts with existing policies and goals leads to few resources, little support, and almost certain failure". This may be a contributing factor to the lack of progress in inclusive policy. Within the Department of Education, there are various sectors that compete for limited resources. The current educational drives are in the expansion of Grade $\mathrm{R}$ (equivalent to kindergarten) and basic adult education programmes, with significantly fewer resources being dedicated to inclusive education (Wildeman \& Nomdo, 2007).

South Africa's inclusive education policy is therefore characterised by both high conflict and ambiguity. Matland $(1995: 160,168)$ terms high conflict, high ambiguity policies as "symbolic implementation" policies, which almost always are associated with non-implementation and failure. Symbolic policies tend to garner attention when they are first passed but ultimately do not come to light; this same pattern is observed in the implementation of inclusive policy. When Education White Paper 6 was first published in 2001, South Africa appeared to be following the international trend toward inclusion, but subsequent policy implementation has made little progress over the past decade. This could in part be related to the ambiguity in both the goals of the policy and the strategic drivers required for its implementation. Sayed and Jansen (2001:1) explain that while South African educational policies have been highly praised throughout the world as a result of their "dazzle", these policies are seldom brought to practice. 
A top-down approach to policy implementation

The education of children with disabilities should not be a racial issue or a political topic. Rather, it should be a human rights concern (Hay \& Beyers, 2011), a sentiment to which the South African government agreed when it became a signatory to the United Nations Convention on the Rights of a Child (Grobbelaar-Du Plessis \& Grobler, 2013), the United Nations Conventions on the Rights of People with Disabilities (UNESCO, 2007) and the Millennium Development Goals (UNESCO, 2000). The inclusive education of a diverse body of children - including those who are diverse in terms of disability, race, gender, religion, language and socioeconomic status - allows children who are different to become acquainted with one another and helps them to discover common ground. In fact, one of the first and foremost locations where attitudinal shifts toward people with disabilities can occur is in schools as this is one of the primary places that early attitudes are formed. By learning these life lessons in childhood, children can develop into adults who are more accepting of a diverse society, which is important when living in a country as diverse as South Africa. Moreover, Engelbrecht (1999) suggests that inclusion is the primary step forward in obtaining a just and equal society.

Currently, the implementation of an inclusive education policy is at an apparent standstill as a result of ambiguity about the means through which the goals of inclusive education can be achieved. Without funding and directives, provincial departments do not possess the ability to make any progress towards implementation. To make significant progress with it, the Department of Education can no longer relegate the responsibility of implementing a policy of their own design to others such as school principals and teachers. Research has found that without support, the burdens associated with implementation quickly become overwhelming to school officials and they swiftly revert back to a special education model of education delivery (Wildeman \& Nomdo, 2007).

In order to initiate progress on inclusive education, the national Department of Education must take some first steps. When addressing school-level barriers to implementation, the Department must determine the extent to which teachers are prepared to educate a diverse body of learners within one classroom. Teachers then need to receive comprehensive training programmes in areas where they lack skills. These training programmes can be supplemented with specialised support teams that have the capacity to enter classrooms and provide teachers with the hands-on training and practical skills that they need to address learners' barriers to learning.

At least in the short term, funding must be increased so that schools can make the infrastructure changes that are needed. Perhaps the educational drives in South Africa can - even temporarily - be shifted from Grade R and adult education to inclusive education. This will provide the much needed attention to and emphasis on the education of learners with disabilities. Besides, the current special education model is not at all cost effective, with the average annual provincial education expenditure for a learner at a special school amounting to R20,870 ( \pm USD\$2,609) compared to R4,587 
( \pm USD\$573) for a learner in an ordinary school (Wildeman \& Nomdo, 2007). These estimates suggest that, in the long term, inclusive education is likely to be significantly more cost effective than the current method of special education delivery.

In addition to training and funding, education officials need clear directives and timetables on how to proceed. These directives should clearly state what is expected of schools and how they should accomplish these goals. If the national Department of Education wants schools to address barriers to learning such as poverty or a lack of parental support, they should suggest the steps by which schools are to do this. Included in these methods should be timelines for expected progress and the penalties that will be given for those schools that do not make acceptable progress.

To address cultural-level barriers to inclusion, the Department of Education must proceed with the information and advocacy programme that was supposed to accompany the implementation of the inclusive education policy (see Department of Education, 2001:33-34). The premise of this programme was to help combat negative perceptions of disability within society and help win support for inclusive policies. The programme was suggested to be necessary since "[p]ublic awareness and acceptance will be essential for the establishment of...inclusive education" (Department of Education, 2001:33). Moreover, with the introduction of the information and advocacy programme, the rights, responsibilities and obligations attached to inclusive policy was supposed to be disseminated to key players. However, a recent study conducted in KwaZulu-Natal (Maher, 2009) found no evidence of the programme having been employed in any regard and revealed that no formal guidelines for the execution of the information and advocacy programme even exist.

In summary, the Department of Education needs to hold itself accountable for the implementation of a policy that it created, especially since inclusive policies are of little meaning and use unless they are implemented and enforced. As a top-down theoretical orientation to policy implementation suggests, progress can be made with inclusive policy in South Africa if procedures are clarified, directives are given, and the appropriate authorities assume responsibility and control of its implementation. Education White Paper 6 (Department of Education, 2001) was a monumental step forward in respect of the rights of people with disabilities in South Africa, but the policy will remain purely symbolic until real initiative and deliberate action are taken.

\section{Conclusion}

Over 10 years following the unveiling of Education White Paper 6 (Department of Education, 2001), most children with disabilities in South Africa are still are not taught in classrooms together with their typically developing peers. However, the inclusion of learners with disabilities into mainstream classrooms, and more generally, the inclusion of people with disabilities into society, is currently conceptualised as a human rights issue - a topic with which most South Africans are quite familiar in their struggle to overcome apartheid. There are many barriers to providing quality and inclusive education to learners with disabilities in South Africa. The situation is far 
from hopeless, though. Inevitably, obstacles to inclusion will thwart progress in both developing and developed countries. Fortunately these obstacles are not insurmountable, and the more children with disabilities are included in education and elsewhere in their communities, the sooner they can become productive and contributing members of society, showcasing their unique talents just like everyone else.

\section{References}

Ainscow M 2002. Using research to encourage the development of inclusive practices. In $\mathrm{P}$ Farrell \& M Ainscow (eds). Making Special Education Inclusive. London: David Fulton.

Anderson KG, Case A \& Lam D 2001. Causes and consequences of schooling outcomes in South Africa: Evidence from survey data. Social Dynamics, 27(1):37-59. doi: $10.1080 / 02533950108458703$

Armstrong P 2009. Teacher pay in South Africa: How attractive is the teaching profession? Stellenbosch Economic Working Papers 04/09. Available at $\mathrm{http} / / /$ ideas.repec.org/p/sza/wpaper/wpapers76.html. Accessed 26 February 2014.

Asmal K \& James W 2001. Education and democracy in South Africa today. Daedalus, 130:185-204.

Bornman J \& Rose J 2010. Believe that all can achieve: Increasing classroom participation in learners with special support needs. Pretoria: Van Schaik.

Campbell J, Gilmore L \& Cuskelly M 2003. Changing student teachers' attitudes towards disability and inclusion. Journal of Intellectual and Developmental Disability, 28(4):369-379. Available at http://eprints.qut.edu.au/4305/1/4305.pdf. Accessed 27 February 2014.

Daudji A, Eby S, Foo T, Ladak F, Sinclair C, Landry MD, Moody K \& Gibson BE 2011. Perceptions of disability among south Asian immigrant mothers of children with disabilities in Canada: Implications for rehabilitation service delivery. Disability and Rehabilitation, 33(6):511-521. doi: 10.3109/09638288.2010.498549

Department of Education 2001. White Paper 6: Special Needs Education - Building an inclusive education and training system. Pretoria: Department of Education. Available at

http://www.education.gov.za/LinkClick.aspx?fileticket=gVFccZLi\%2FtI\%3D\&tabid=1 $91 \& \mathrm{mid}=484$. Accessed 26 February 2014.

Department of Education 1995. White Paper on Education and Training in a Democratic South Africa: First steps to developing a new system. Government Gazette 357(16312). Pretoria: Government Printer.

Engelbrecht P 2006. The implementation of inclusive education in South Africa after ten years of democracy. European Journal of Psychology of Education, 21(3):253-264. Available at http://download.springer.com/static/pdf $/ 625$ art\%253A10.1007\%252FBF03173414.pdf?auth66=1393688373_906fca13d83dd82e8df f7e7b10f80b93\&ext=.pdf. Accessed 27 February 2014.

Engelbrecht P 1999. A theoretical framework for inclusive education. In P Engelbrecht, L Green, S Naicker \& L Engelbrecht (eds). Inclusive education in action in South Africa. Pretoria: Van Schaik.

Frankel EB, Gold S \& Ajodhia-Andrews MA 2010. International preschool inclusion: Bridging the gap between vision and practice. Young Exceptional Children, 13(5):2-16. doi: $10.1177 / 1096250610379983$

Grobbelaar-Du Plessis I \& Grobler C 2013. South Africa. African Disability Rights 
Yearbook, 1:307-340. Available at http://www.pulp.up.ac.za/pdf/2013_07/2013_07.pdf. Accessed 10 March 2014.

Groce NE 2004. Adolescents and youth with disability: issues and challenges. Asia Pacific Disability Rehabilitation Journal, 15(2):13-32. Available at http://eprints.ucl.ac.uk/15132/1/15132.pdf. Accessed 27 February 2014.

Hay J \& Beyers C 2011. An analysis of the South African model of inclusive education with regard to social justice. Africa Education Review, 8(2):234-246. doi:

$10.1080 / 18146627.2011 .603226$

Heap M, Lorenzo T \& Thomas J 2009. 'We've moved away from disability as a health issue, it's a human rights issue': Reflecting on 10 years of the right to equality in South Africa. Disability \& Society, 24(7):857-868. doi: 10.1080/09687590903283464

Hosegood V, Preston-Whyte E, Busza J, Moitse S \& Timaeus IM 2007. Revealing the full extent of households' experience of HIV and AIDS in rural South Africa. Social Science \& Medicine, 65(6):1249-1259. doi: 10.1016/j.socscimed.2007.05.002

Jackson H \& Mupedziswa R 1988. Disability and rehabilitation: Beliefs and attitudes among rural disabled people in a community based rehabilitation scheme in Zimbabwe. Journal of Social Development in Africa, 3(1):21-30. Available at http://archive.lib.msu.edu/DMC/African\%20Journals/pdfs/social\%20development/vol3 no1/jsda003001005.pdf. Accessed 27 February 2014.

Jansen JD 2001. Symbols of change, signals of conflict. In A Kraak \& M Young (eds). The Implementation of Education Policies, 1990-2000. Pretoria: Human Sciences Research Council.

Lam D, Ardington C \& Leibbrandt M 2008. Schooling as a lottery: Racial differences in school advancement in urban South Africa. Working Paper Series number 18. Cape Town: SALDRU, University of Cape Town. Available at http://ideas.repec.org/p/ldr/wpaper/18.html. Accessed 27 February 2014.

Loeb ME \& Eide AH (eds.) 2004. Living conditions among people with activity limitations in Malawi: A national representative study. Oslo: SINTEF Health Research. Available at http://www.safod.org/Images/LCMalawi.pdf. Accessed 25 November 2012.

Lomofsky L \& Lazarus S 2001. South Africa: First steps in the development of an inclusive education system. Cambridge Journal of Education, 31(3):303-317. doi: $10.1080 / 03057640120086585$

Maher M 2009. Information and advocacy: Forgotten components in the strategies for achieving inclusive education in South Africa? Africa Education Review, 6(1):19-36. doi: $10.1080 / 18146620902857251$

Maloni PK, Despres ER, Habbous J, Primmer AR, Slatten JB, Gibson BE \& Landry MD 2010. Perceptions of disability among mothers of children with disability in Bangladesh: Implications for rehabilitation service delivery. Disability and Rehabilitation, 32(10):845-854. doi: 10.3109/09638280903326063

Masasa R, Irwin-Carruthers S \& Faure M 2005. Knowledge of, beliefs about and attitudes to disability: implications for health professionals. South African Family Practice, 47(7):40-44.

Matland RE 1995. Synthesizing the implementation literature: The ambiguity-conflict model of policy implementation. Journal of Public Administration and Theory, 5(2):145-174.

McEwan C \& Butler R 2007. Disability and development: different models, different places. Geography Compass, 1(3):448-466. doi: 10.1111/j.1749-8198.2007.00023.x

Muthukrishna N \& Schoeman M 2000. From 'special needs' to 'quality education for all': A participatory approach to policy development in South Africa. International Journal of Inclusive Education, 4(4):315-335. doi: 10.1080/13603110050168023 
Nel N, Müller H \& Rheeders E 2011. Support services within inclusive education in Gauteng: The necessity and efficiency of support. Mevlana International Journal of Education, 1(1):38-53. Available at http://mije.mevlana.edu.tr/archieve/issue 1 1/4-MIJE-11-03 volume 1 issue 1 page 38 53.pdf. Accessed 27 February $20 \overline{14}$.

Ntombela S 2011. The progress of inclusive education in South Africa: Teachers' experiences in a selected district, KwaZulu-Natal. Improving Schools, 14(1):5-14. doi: $10.1177 / 1365480210390082$

Oswald M \& Swart E 2011. Addressing South African pre-service teachers' sentiments, attitudes and concerns regarding inclusive education. International Journal of Disability, Development and Education, 58(4):389-403. doi: 10.1080/1034912X.2011.626665

Pivik J, McComas J \& Laflamme M 2002. Barriers and facilitators to inclusive education. Exceptional Children, 69(1):97-107. Available at http:/www.itari.in/categories/facilitators/ researchbyfacilitatorsforspecialchildren.pdf. Accessed 28 February 2014.

Polat F 2011. Inclusion in education: A step towards social justice. International Journal of Educational Development, 31(1):50-58. http://dx.doi.org/10.1016/j.ijedudev.2010.06.009

Sayed Y \& Jansen JD (eds.) 2001. Implementing Education Policies: The South African Experience. Cape Town: University of Cape Town.

Scruggs TE \& Mastropieri MA 1996. Teacher perceptions of mainstreaming/inclusion, 1958-1995: a research synthesis. Exceptional Children, 63(1):59-74.

Statistics South Africa 2011. Available at http://beta2.statssa.gov.za/. Accessed 15 December 2012.

Stofile SY 2008. Factors affecting the implementation of inclusive education policy: A case study in one province in South Africa. PhD thesis. Cape Town: University of the Western Cape. Available at http://etd.uwc.ac.za/usrfiles/modules/ etd/docs/etd_gen8Srv25Nme4_7965_1269472515.pdf. Accessed 3 March 2014.

Wildeman RA \& Nomdo C 2007. Implementation of Inclusive Education: How far are we? Occasional Paper, Idasa Budget Information Service.

World Health Organization (WHO) 2012. Health topics: Disabilities. Available at http://www.who.int/topics/disabilities/en/. Accessed 3 December 2012.

United Nations Educational, Scientific, and Cultural Organization (UNESCO) 2007. Convention on the Rights of Persons with Disabilities [A/RES/61/106]. Available at http://www.un.org/disabilities/default.asp?id=199. Accessed 3 March 2014.

UNESCO 2000. World education forum Dakar, Senegal, 26-28 April. Paris, France: UNESCO. Available at http://www.unesco.org/education/wef/en-docs/ findings/rapport\%20final\%20e.pdf. Accessed 3 March 2014.

UNESCO 1990. One billion illiterates: a challenge for our time. Unesco Courier, July.

Van der Berg S 2007. Apartheid's enduring legacy: Inequalities in education. Journal of African Economies, 16(5):849-880. doi: 10.1093/jae/ejm017

Zollers NJ, Ramanathan AK \& Yu M 1999. The relationship between school culture and inclusion: How an inclusive culture supports inclusive education. Qualitative Studies in Education, 12(2):157-174. doi: 10.1080/095183999236231 